Cite this: J. Mater. Chem. B, 2014, 2, 718

Received 23rd July 2013

Accepted 11th November 2013

DOI: $10.1039 / c 3 t b 21015 d$

www.rsc.org/MaterialsB

\section{Functionalized large pore mesoporous silica nanoparticles for gene delivery featuring controlled release and co-delivery $\dagger$}

\author{
Sandy Budi Hartono, ${ }^{a}$ Nghia Truong Phuoc, ${ }^{a}$ Meihua Yu, ${ }^{a}$ Zhongfan Jia, ${ }^{a}$ \\ Michael J. Monteiro, ${ }^{* a}$ Shizhang Qiao*b and Chengzhong Yu*a
}

\begin{abstract}
Novel mesoporous silica nanoparticles (LPMSNs) functionalised with degradable poly(2-dimethylaminoethyl acrylate) (PDMAEA) have been developed (PDMAEA-LPMSNs) as nano-carriers for gene delivery. The unique design of PDMAEA-LPMSNs has endowed this system with multiple functions derived from both the organic and inorganic moieties. The cationic polymer unit binds to genetic molecules and undergoes a self-catalyzed hydrolysis in water to form a non-toxic anionic polymer poly(acrylic acid), allowing controlled release of siRNA in the cells. The nanopores of the LPMSNs provide a reservoir for storage and release of chloroquine to facilitate endosomal escape. The PDMAEA-LPMSN composites were characterized by elemental analysis (EA), X-ray photoelectron spectroscopy (XPS), solid-state ${ }^{13} \mathrm{C}$ magic-angle spinning nuclear magnetic resonance (MAS-NMR), thermogravimetric analysis (TGA), and nitrogen sorption techniques. Their siRNA delivery performance was tested in a KHOS cell line, showing promising potential for co-delivery of genes and drugs.
\end{abstract}

\section{Introduction}

Small interfering RNA (siRNA) based therapeutics has received increasing attention for cancer treatment applications. ${ }^{1}$ The siRNA therapy features highly specific siRNA to silence oncogenes. However, the vulnerability of siRNA to nucleases and its poor cellular delivery hampers in vivo applications. ${ }^{2} \mathrm{Nano}^{-}$ carriers that can package, protect and deliver siRNA to the targeted site hold promise for solving these problems for practical applications in siRNA therapy. ${ }^{3}$

Various nanocarriers have been developed for delivery of siRNA, such as lipid and polymer based carriers. ${ }^{4}$ Inorganic materials (e.g. gold, iron oxide and silica materials) have also been studied as carriers for genetic molecules. ${ }^{5-8}$ Recently, mesoporous silica nanoparticle (MSN) based materials have shown promising performance as gene carriers. ${ }^{\mathbf{9 - 1 1}}$ Various surface modified MSN have been systematically studied to deliver siRNA. Short amine silane moieties have been extensively used to increase silica affinity towards the nucleic acid agents (DNA, siRNA). ${ }^{9-11}$ Meng et al. used polyethyleneimine (PEI)

${ }^{a}$ Australian Institute for Bioengineering and Nanotechnology, The University of Queensland, Brisbane, QLD 4072, Australia.E-mail: m.monteiro@uq.edu.au; c.yu@ uq.edu.au

${ }^{b}$ School of Chemical Engineering, The University of Adelaide, Adelaide, Australia. E-mail: s.qiao@adelaide.edu.au

$\dagger$ Electronic supplementary information (ESI) available: Nitrogen sorption and TGA analysis of LPMSN, A-MSN and PDMAEA-LPMSN; high resolution XPS analysis for A-MSN and PDMAEA-LPMSN. See DOI: 10.1039/c3tb21015d modified MSNs with different molecular weights to enhance the efficacy of siRNA. ${ }^{\mathbf{1 2}}$ In addition, polyamine dendrimer-MSNs have also been used for delivering siRNA. ${ }^{13}$ Composite materials consisting of both polymer and mesoporous silica combine the benefits from each component to create a more advanced carrier system. ${ }^{\mathbf{8 , 1 3 , 1 4}}$ Polycation or polyamine complexes with MSN are more versatile compared to the short chain amine-MSNs. The presence of multi amine moieties significantly enhances particle affinity towards siRNA and the cell membrane. ${ }^{15}$

The main issue related to the polycation complex with siRNA (polyplex) is the strong binding between the abundant positive charge on the polymer and the negatively charged phosphonic acid of the nucleic acid, which hinders the release of siRNA within the cytoplasm thus lowering the efficacy of the siRNA. ${ }^{\mathbf{1 6 , 1 7}}$ This factor is also known as vector unpacking. To exert siRNA function, it needs to be transferred into the cytoplasm and released from the carrier as free molecules which can induce gene silencing. ${ }^{18,19}$ The second issue is the cytotoxicity of the polycation. ${ }^{17}$ This condition raises a concern about the accumulated toxicity of the nanoparticles, especially after multiadministration. Previously, we have reported the use of poly-Llysine (PLL) functionalised large pore mesoporous silica nanoparticles (LPMSN-P) as gene carriers. ${ }^{15}$ The PLL-functionalized nanoparticles bound strongly to the nucleic acid molecules and delivered oligo DNA-Cy3 (a model for siRNA) efficiently to HeLa cells. However, the low release of siRNA from the complex limited the effectiveness of this system.

Degradable polycationic polymers that can be degraded into non-toxic compounds and enhance gene release are preferable 
as carriers in gene therapy. ${ }^{\mathbf{1 6}}$ Several methods have been used to establish degradable structures by introducing cleavable bonds into the polymer structures. The cleavable bonds include esters, amides, carbonates and disulfides. Most of these structures depend on various external triggers $(\mathrm{pH}$, redox potential and enzymes) to start the degradation. ${ }^{\mathbf{1 7 2 0 - 2 2}}$ However, the high fluctuation of these triggers within the human body might cause inconsistency in the cleavage reactions, resulting in variable and unpredictable rates of degradation. ${ }^{23,24}$ It is desirable to use a cleavable polymer that degrades only after being internalized by target cells in a simple and controlled manner. ${ }^{23,24}$

Recently, a self-catalyzed degradable cationic polymer (poly(2dimethylaminoethyl acrylate), PDMAEA), which degrades independently of an external degradation trigger, has been developed..$^{23-25}$ The degradation product is poly(acrylic acid), PAA, which is non-toxic. The most prominent features of this polymer are the ability to bind and protect oligo-DNA for sufficient time and the capacity to release the DNA inside the cells after 10 hours. ${ }^{23-25}$ In this work, we used PDMAEA covalently attached to the surface of large pore mesoporous silica nanoparticles (PDMAEA-LPMSNs) to act as a dual delivery system. The surface bound PDMAEA can bind and release siRNA 'on-demand'. Chloroquine was loaded in the nanopores of the LPMSNs as a model drug which helps endosomal escape. It was shown that PDMAEA-LPMSNs released oligo-DNA(mimicking siRNA) within 2 days of incubation, while little release was observed from the polyethyleneimine (PEI) functionalized LPMSNs. In the delivery of a functional siRNA (PLK1), chloroquine loaded PDMAEALPMSNs inhibited the viability of KHOS cancer cells significantly compared to PDMAEA-LPMSNs, showing the advantage of a carefully designed composite co-delivery system.

\section{Experimental section}

\section{Chemicals}

Triblock poly(ethylene oxide)- $b$-poly(propylene oxide)- $b$-poly(ethylene oxide) copolymer $\mathrm{EO}_{106} \mathrm{PO}_{70} \mathrm{EO}_{106}$ (Pluronic F127, MW $=13$ 400), tetraethoxysilane (TEOS, 99\%), 1,3,5-trimethylbenzene (TMB), copper(I) bromide, 3-glycidoxypropyl trimethoxysilane (3-GPS), 3-aminopropyltriethoxysilane (APTES, 99\%), sodium azide, ethyl 2-chloropropionate (97\%), copper powder (size $<425 \mu \mathrm{m}, 99.5 \%$ trace metals basis), tris[2-(dimethylamino)ethyl]amine were used as received from Sigma Aldrich. A fluorocarbon surfactant (FC-4) was purchased from Yick-Vic Chemicals \& Pharmaceuticals (HK) Ltd. 2-(Dimethylamino) ethyl acrylate (98\%), $N, N$-dimethylacrylamide (99\%) were passed through a column of basic alumina to remove the inhibitor before use. $n$-Hexane (>98\%), dichloromethane (99.8\%), and methanol (99.8\%) were used as received from Merck. Polyethyleneimine (PEI) (MW: $10 \mathrm{kDa}$ ) were purchased from Alfa Aesar (Ward Hill, MA). All chemicals were used as received without purification. Cell lines used: osteosarcoma cell line KHOS/NP (CRL-1544 ${ }^{\mathrm{TM}}$ ) was purchased from ATCC (American Type Culture Collection). Twenty-one-nucleotide (oligo) DNA conjugated with cyanine dye (Cy-3), fetal calf serum, paraformaldehyde and anti-fade fluorescent mounting medium with 4'-6-diamidino-2-phenylindole (DAPI) were purchased from Sigma Aldrich. Dulbecco's Modified Eagle's Medium (DMEM) and penicillin G, streptomycin sulphate and L-glutamine mixture were from Gibco-Invitrogen. The CellTiter-Glo ${ }^{\circledR}$ cell viability assay kit was from Promega. Synthetic human PLK1 was purchased from Ambion at Applied Biosystems (Foster City, CA). The siRNA sequences are: PLK-S: 5'-CCAUUAACGAGCUG CUUAATT-3' ; PLK-AS: 5' -UUAAGCAGCUCGUUAAUGGTT-3' ' S10siRNA was synthesized by Proligo (Lismore, Australia) and the sequence: S10-S: 5'-GCAACAGUUACUGCGACGUUU-3'; S10-AS: 5'-ACGUCGCAGUAACUGUUGCUU- ${ }^{\prime}$.

\section{Synthesis of LPMSNs}

LPMSNs were synthesised following a previous method by Ying et al. ${ }^{26}$ First, $0.5 \mathrm{~g} \mathrm{~F} 127$ and $1.4 \mathrm{~g}$ of FC- 4 were dissolved in $60 \mathrm{ml}$ of $0.02 \mathrm{M} \mathrm{HCl}$ and stirred for 24 hours at $60^{\circ} \mathrm{C} .0 .4 \mathrm{~g}$ of TMB was added into the mixture and stirred at a temperature of $30^{\circ} \mathrm{C}$ for 6 hours. Then, $3 \mathrm{~g}$ of TEOS was added to the solution, and the stirring process was continued at $30{ }^{\circ} \mathrm{C}$ for another 24 hours. The solution was then transferred into autoclaves for hydrothermal treatment. The hydrothermal temperature was at $100{ }^{\circ} \mathrm{C}$ for 24 hours. The sample was denoted as as-synthesized LPMSNs (AS-LPMSNs). The surfactant (F-127) still remained within the pores of the AS-LPMSNs.

\section{Synthesis of 2-bromo- $\mathrm{N}$-(3-(triethoxysilyl)propyl)propanamide}

BPB in $50 \mathrm{ml}$ DCM was added dropwise to a cold solution of APTS and TEA in $200 \mathrm{ml}$ dry DCM. The solution was stirred for $30 \mathrm{~min}$ at room temperature and the precipitate was filtered off. The solution was washed with acidic water and dried with magnesium sulphate. After filtration the solvent was removed using a rotavapor. The product was dried under vacuum for 24 hours.

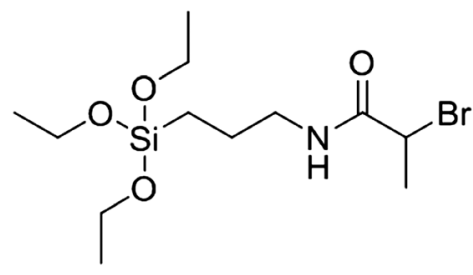

\section{Azidation of 2-bromo- $\mathrm{N}$-(3-(triethoxysilyl)-propyl) propanamide or azide silane}

BPTS was dissolved in dry DMF and $\mathrm{NaN}_{3}$ was added. The mixture was stirred for 48 hours at room temperature. The solution was then diluted with $200 \mathrm{ml}$ of DCM, washed with water and concentrated by evaporation. The product was dried under vacuum for 24 hours.

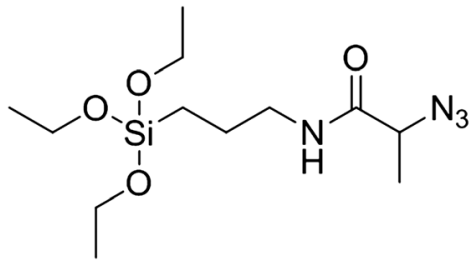




\section{Synthesis of poly(2-dimethylaminoethyl acrylate) (PDMAEA)} by SET-LRP $^{27}$

$\mathrm{CuCl}_{2} / \mathrm{Me}_{6} \mathrm{TREN}\left(32 \mathrm{mg}, 8.8 \times 10^{-5} \mathrm{~mol}\right.$ ), $\mathrm{Me}_{6}$ TREN (61 mg, $\left.2.6 \times 10^{-4}\right)$, ethyl 2-chloropropanoate $\left(120 \mathrm{mg}, 8.8 \times 10^{-4}\right.$ $\mathrm{mol}$ ) and 2-dimethylaminoethyl acrylate (DMAEA, $18.9 \mathrm{~g}$, $0.132 \mathrm{~mol})$ were dissolved in isopropanol $(10 \mathrm{ml})$ and the solution was purged with argon for 30 minutes at room temperature. $\mathrm{Cu}$ powder (size $<425 \mu \mathrm{m}$ ) was added under an argon flow. After 7 hours of polymerisation at room temperature, the solution was diluted with acetone $(100 \mathrm{ml})$ and passed through $\mathrm{Al}_{2} \mathrm{O}_{3}$ to remove the copper. Acetone was removed using the rotavap, and the product was obtained by precipitation in a large excess of cold $n$-hexane $(500 \mathrm{ml})$ and then isolated by centrifugation. This procedure was repeated three times. The polymer was dried under a high vacuum for 48 hours at room temperature to give a yellow oily product (yield $70 \%$ ). The conversion of the polymerization was $40 \%$ as determined by ${ }^{1} \mathrm{H}$ NMR spectroscopy. $M_{\mathrm{n}}=4200$, PDI $=1.29$ (SEC-RI calibrated using P(STY) standards and DMAc +0.03 wt\% LiCl was used as the eluent).

\section{Synthesis of azide-MSNs (A-MSNs) and PDMAEA-LPMSNs}

To establish azide groups on the surface of the LPMSNs, $5.3 \mathrm{mg}$ 2-azido- $N$-(3-(triethoxy silyl)propyl)propanamide or azide silane was grafted onto $100 \mathrm{mg}$ AS-LPMSNs in $25 \mathrm{ml}$ toluene. The reaction was maintained at $70{ }^{\circ} \mathrm{C}$ for 24 hours. The product was washed with toluene and methanol and followed by surfactant removal. The surfactant removal was conducted using an extraction process in acidic-methanol for 24 hours and the process was repeated three times. The product is named A-MSNs. A-MSNs have an opened pore structure.

Finally, a click reaction between alkyne-poly(2-dimethylaminoethyl acrylate) (PDMAEA) and A-MSN also known as the Huisgen 1,3-dipolar cyclo-addition can be conducted. $100 \mathrm{mg}$ A-MSNs and $578 \mathrm{mg}$ PDMAEA was mixed in $2 \mathrm{ml}$ of toluene at a room temperature under argon, followed by addition of $9 \mu \mathrm{l}$ of PMDETA. Then, $6 \mathrm{mg}$ of copper bromide $(\mathrm{CuBr})$, as a catalyst, was added to the mixture. The reaction was maintained for 24 hours. The product PDMAEA-LPMSNs were washed and dried in a vacuum.

\section{Synthesis of PEI-LPMSNs}

First the epoxysilane was attached onto the silica surface: 100 $\mathrm{mg}$ of LPMSNs were mixed in $30 \mathrm{ml}$ of toluene and stirred for 15 minutes at $70{ }^{\circ} \mathrm{C} .1 .5 \mathrm{ml}$ of 3-GPS was added into the solution and further stirred for 24 hours at the same temperature. The solid products (epoxy-LPMSNs) were centrifuged, washed with toluene and methanol three times, and dried. The next step was to graft PEI onto the epoxy-LPMSNs: $80 \mathrm{mg}$ of epoxy modified particles were mixed with $200 \mathrm{mg}$ PEI $(10 \mathrm{kDa})$ in $100 \mathrm{ml}$ of carbonate buffer (50 mM, pH 9.5) for 24 hours at room temperature. After this step, the solid product was produced and washed with $20 \mathrm{ml}$ of $1.0 \mathrm{M} \mathrm{NaCl}$ and water three times, then centrifuged. At the final stage, the solid products were suspended in $20 \mathrm{ml}$ of $1.0 \mathrm{M}$ ethanolamine ( $\mathrm{pH}$ 9) and stirred at room temperature for 6 hours to block unreacted epoxy groups. The solids were again washed with $20 \mathrm{ml}$ of $1.0 \mathrm{M} \mathrm{NaCl}$ and $20 \mathrm{ml}$ water.

\section{Adsorption of chloroquine onto the PDMAEA-LPMSNS}

$100 \mathrm{mg}$ of A-MSNs were mixed with $80 \mathrm{ml}$ of chloroquine (Chl) solution $\left(100 \mathrm{mg} \mathrm{ml}^{-1}\right)$. The suspension was incubated for 24 hours at room temperature under constant stirring. The suspension was then separated by centrifugation. The ChI concentration was determined before and after incubation using UV-vis at a wavelength of $329 \mathrm{~nm}$. The difference in Chl amounts is determined as the amount of Chl absorbed on the material. The adsorption was then followed by PDMAEA attachment onto Chl loaded A-MSN. The sample is denoted Chl-PDMAEA-LPMSN.

\section{Oligo DNA adsorption and release analysis}

Oligo DNA was complexed with PDMAEA-LPMSN (or PEILPMSN) at 2 different nitrogen to phosphorous ratios (N/P) $(\mathrm{N} / \mathrm{P}=1$ and 10$)$. The complex was mixed in $25 \mu \mathrm{l}$ of water for 30 minutes at room temperature. Oligo DNA and LPMSNoligo DNA were used as controls. The agarose gel retardation assay was initiated by adding $5 \mu$ DNA loading dye into the complex which was then loaded into a $2 \%$ agarose gel containing TAE buffer and stained with ethidium bromide. The gels were run in $1 \times$ TAE buffer for around 10 minutes at $80 \mathrm{~V}$ and then followed by observation under a Bio-Rad UV transilluminator.

\section{Cytotoxicity test}

The cytotoxicity of the PDMAEA-LPMSNs and the ChlPDMAEA-LPMSNs in KHOS cells were tested by Cell-Titer Glo assay. KHOS cells were seeded in a 96-well cell culture plate with a density of $5 \times 10^{3}$ cells per well. After incubation for 24 hours, the cells were treated with different concentrations of PDMAEA-LPMSN and Chl-PDMAEA-LPMSN solution, followed by further incubation at $37{ }^{\circ} \mathrm{C}$ for 48 hours. The cell viability of KHOS cells was evaluated using a Cell-Titer Glo assay, according to the protocol provided by the manufacturer. The cells incubated in the absence of particles were used as the control. All the experiments were performed in triplicates for each group. The statistical data are shown as mean $\pm(\mathrm{SD})$.

\section{Cellular uptake (confocal microscopy)}

KHOS cells were maintained in Dulbecco's Modified Eagle Medium (DMEM) supplemented with fetal calf serum (10\%), $\mathrm{L}^{-}$ glutamine $(2 \%)$, penicillin $(1 \%)$, streptomycin $(1 \%)$ in $5 \% \mathrm{CO}_{2}$ at $37{ }^{\circ} \mathrm{C}$. The medium was routinely changed every 2 days and the cells were separated by trypsinisation before reaching confluency. KHOS cells were seeded in a 6 -well plate $\left(1 \times 10^{5}\right.$ cells per well) and incubated for 24 hours prior to the cell uptake assay. $50 \mu \mathrm{g}$ of PDMAEA-LPMSNs or Chl-PDMAEALPMSNs and $2 \mu \mathrm{l}$ of $100 \mu \mathrm{M}$ Cy3-oligoDNA was mixed in $100 \mu \mathrm{l}$ of phosphate buffered saline (PBS) solution and incubated at 
$4{ }^{\circ} \mathrm{C}$ overnight. After incubation, the mixture was added to a well in a 6-well plate containing $2.0 \mathrm{ml}$ of serum-free DMEM medium, and the final concentrations of nanoparticles and Cy3-oligoDNA were $25 \mu \mathrm{g} \mathrm{ml}^{-1}$ and $100 \mathrm{nM}$, respectively. After incubation for 4 hours at $37{ }^{\circ} \mathrm{C}$, the cells were washed twice with PBS to remove the remaining nanoparticles, free Cy3oligoDNA and dead cells. For fixed cell imaging, the cells were treated with $500 \mu \mathrm{l}$ of $4 \%$ PFA PBS solution for 30 minutes at $4{ }^{\circ} \mathrm{C}$, and their nuclei were stained with DAPI for 10 minutes. Finally, the cells were observed under a confocal microscope (LSM Zeiss 710).

\section{siRNA function}

To examine whether the particles (PDMAEA-LPMSN and ChlPDMAEA-LPMSN) can deliver functional molecules to cells for therapy, we chose siRNAs against human PLK1 genes (PLK1siRNA). An ineffective siRNA, S10-siRNA, was chosen as a negative control because S10-siRNA is effective only against human papillomavirus (HPV) type E6 gene, while there is no HPV in KHOS cells. The cells were seeded at $5 \times 10^{3}$ cells per well in $100 \mu \mathrm{l}$ of complete DMEM medium in a 96-well plate and cultured overnight before treatment. The siRNA was absorbed onto particles as described above (for 21-nucleotide oligo DNA adsorption) and were added to the cells. The cells were treated for 48 hours and the silencing effect or cell viability was determined by Cell-Titer Glo assay.

\section{Characterization}

Transmission electron microscopy (TEM) images were obtained using a JEOL 1010 electron microscope with an acceleration voltage $100 \mathrm{kV}$. Scanning electron microscopy (SEM) images were recorded using a JEOL 6300 microscope operated at 5-10 kV. Nitrogen sorption isotherms of the samples were obtained using a Quantachrome's Quadrasorb SI analyser at $77 \mathrm{~K}$. Before the measurements, the samples were degassed overnight at $110{ }^{\circ} \mathrm{C}$ in a vacuum. The BrumauerEmmett-Teller (BET) surface area was calculated using experimental points at a relative pressure of $P / P_{0}=0.05-0.25$. The total pore volume was calculated from the amount of $\mathrm{N}_{2}$ adsorbed at the highest $P / P_{0}\left(P / P_{0}=0.99\right)$. The pore size distribution was calculated using the Broekhoff-de Boer (BdB) method using a spherical model. The cavity pore size and entrance pore size are determined from the adsorption and desorption branches, respectively, using the BdB method. XPS spectra were recorded on a Kratos Axis Ultra with a monochromatic $\mathrm{Al} \mathrm{K}_{\alpha} \mathrm{X}$-ray source. Each spectrum was recorded by a survey scan from 0 to $1200 \mathrm{eV}$ with a dwell time of $100 \mathrm{~ms}$, a pass energy of $160 \mathrm{eV}$ at steps of $1 \mathrm{eV}$ with 1 sweep. A high resolution scan was conducted at a lower pass energy $(20 \mathrm{eV})$, higher sweep and dwell time at $250 \mathrm{~ms}$. C1s with a binding energy of $285 \mathrm{eV}$ was used as the reference. The atomic ratio of the LPMSNs and their functionalised forms (A-MSNs and PDMAEA-LPMSNs) were determined from XPS spectra and elemental analysis. Solid state magic-angle spinning (MAS) ${ }^{13} \mathrm{C}$ nuclear magnetic resonance (NMR) measurements were performed with a Bruker MSL-300 spectrometer operating at a frequency of $75.482 \mathrm{MHz}$ for ${ }^{13} \mathrm{C}$. The spectrometer was equipped with a $4 \mathrm{~mm}$ double air bearing, magic angle spinning probe for MAS experiments. The proton $90^{\circ}$ pulse time used in the CPMAS method was $5.5 \mu \mathrm{s}$, the acquisition time was $45 \mathrm{~ms}$, cross-polarisation time $2 \mathrm{~ms}$ and the relaxation delay was $3 \mathrm{~s}$. The spectrum width was $50 \mathrm{kHz}$, and 4000 data points were collected over 2000 scans. The chemical shifts in the ${ }^{13} \mathrm{C}$ spectrum were referenced to the resonance of adamantine at $38.23 \mathrm{ppm}$. All samples were equilibrated at room temperature $\left(22^{\circ} \mathrm{C}\right)$. Zeta potential measurements were conducted on a Zetasizer Malvern Instrument. TGA/DSC 1 (Mettler-Toledo AG) was used for thermogravimetric analysis (TGA) at a heating rate of $2{ }^{\circ} \mathrm{C} \min ^{-1}$ under a nitrogen flow of $20 \mathrm{ml} \min ^{-1}$.

\section{Results and discussion}

Fig. 1A shows the spherical like morphology of LPMSNs with particle sizes of approximately 100-200 nm. The submicron spherical morphology can also be confirmed from SEM analysis (Fig. 2). Nitrogen sorption analysis of the LPMSNS demonstrates a type IV isotherm with a $\mathrm{H} 2$ hysteresis loop at high relative pressure indicating the existence of large mesopores with cage-like structures (Fig. S1†). The size of the cavities in the LPMSNs was determined to be $11 \mathrm{~nm}$. The main characteristic of the LPMSNs is the cubic pore structure with a high degree of pore interconnectivity allowing superior mass transfer compared to one-dimensional channel-like structures. This structure also makes the nanoparticles more resistant to pore blocking. ${ }^{7,15}$

PDMAEA $\left(M_{\mathrm{n}} \sim 4200\right)$ (Fig. S2A $\dagger$ ) was attached to the LPMSNs through a linking azide silane agent $(250 \mathrm{Da}$, Fig. S2B †). The TEM image of the PDMAEA-LPMSNs (Fig. 1B) reveals that the functionalization process does not affect the cubic pore structure. The elemental analysis (EA) indicates that there is an increase in the atomic percentage of nitrogen $(\mathrm{N})$, after azide attachment, to $1.05 \%$. The nitrogen content on the surface of the LPMSNs was also detected by XPS analysis with an atomic ratio of $1.33 \%$ (Table 1 ). Similar results are also confirmed after PDMAEA attachment. There are significant increases in the $\mathrm{C}$ and $\mathrm{N}$ percentages after polymer attachment. The carbon composition rose from $6.9 \%$ to $15.5 \%$ and $13.6 \%$ to $59.5 \%$ when measured by EA and XPS analysis respectively. On

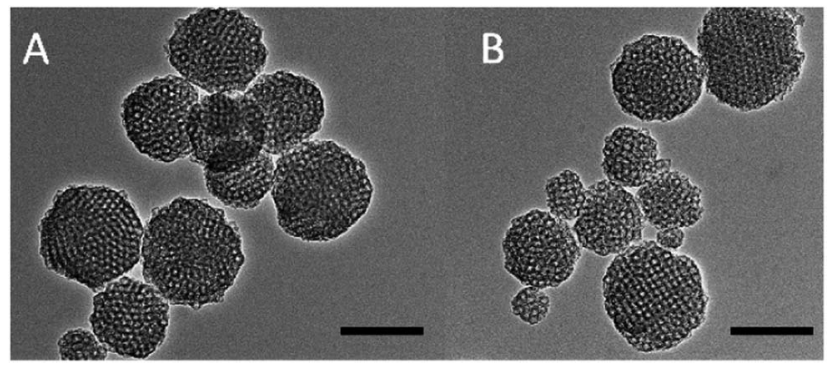

Fig. 1 TEM images of (A) LPMSNs and (B) PDMAEA-LPMSNs (scale bar: $100 \mathrm{~nm})$. 


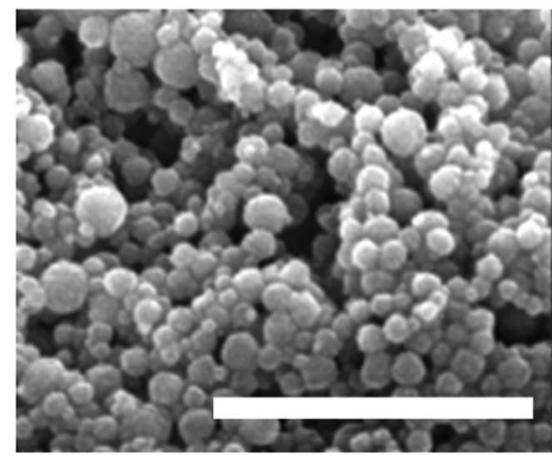

Fig. 2 SEM image of LPMSNs (scale bar: $1 \mu \mathrm{m}$ ).

Table 1 Chemical composition of the composite PDMAEA-LPMSNs

\begin{tabular}{lccccccccr}
\hline & \multicolumn{2}{l}{ Elemental analysis } & & XPS & & & \\
\cline { 2 - 3 } & $\% \mathrm{~N}$ & $\% \mathrm{C}$ & $\% \mathrm{H}$ & & $\% \mathrm{~N}$ & $\% \mathrm{C}$ & $\% \mathrm{O}$ & $\% \mathrm{Si}$ \\
\hline LPMSNs & - & 7.54 & 1.68 & - & 12.25 & 62.27 & 25.47 \\
A-MSNs & 1.05 & 6.99 & 1.59 & & 1.33 & 13.62 & 59.18 & 25.87 \\
PDMAE-LPMSNs & 3.47 & 15.5 & 2.86 & & 5.12 & 59.55 & 28.77 & 6.55
\end{tabular}

the other hand, the nitrogen concentration increased to 3.5\% and $5.1 \%$ based on EA and XPS analysis. TGA analysis confirms that around 5\% weight of azide and $16 \%$ weight of PDMAEA have been grafted onto the LPMSNs (Fig. S3 $\uparrow$ ).

The details of the surface modification achieved on the silica materials can be seen from the XPS analyses of N1s for the AMSNs and the PDMAEA-LPMSNs (Fig. S4 $\dagger$ ). Fig. S4A $\dagger$ is a typical N1s spectrum for azide moieties. There are two peaks representing $\mathrm{N}^{+}$species and $\mathrm{N}^{-}$species. ${ }^{28}$ After PDMAEA attachment, only one single peak of N1s is observed (Fig. S4B†े). This indicates that most of the nitrogen atoms in the azide groups have reacted with the alkyne groups of PDMAEA. Thus only $\mathrm{C}-\mathrm{N}$ binding from the PDMAEA repeating unit can be detected. That is why only one single peak, instead of two single peaks, is observed.

Furthermore, we use ${ }^{13} \mathrm{C}$ NMR analysis to confirm the successful attachment of PDMAEA and to reveal the molecular structure of PDMAEA-LPMSN. Fig. 3 shows the solid state ${ }^{13} \mathrm{C}$ CP-MAS-NMR spectrum of the PDMAEA-LPMSNs. The peaks at $9.5 \mathrm{ppm}\left(\mathrm{C}^{1}\right)$ represent the covalent attachment of PDMAEA onto the LPMSNs via azide silane bridges. The peaks of $\mathrm{C}^{5}, \mathrm{C}^{*}$ and $\mathrm{C}^{7}$ confirm successful binding between azide groups and alkyne groups of PDMAEA. ${ }^{29,30}$ The chemical shifts of the ${ }^{13} \mathrm{C}$ NMR resonances of the PDMAEA-LPMSN samples are compiled in Table 2. The chemical bindings can be revealed and attributed to the structure of PDMAEA. In addition, the introduction of PDMAEA produced positive charges on the silica surface, resulting in a positive PDMAEA-LPMSN potential value $(+20 \mathrm{mV}$ as compared to LPMSNs with $-14.0 \mathrm{mV}$ ).

Fig. S1 $\uparrow$ shows the nitrogen sorption profile of the LPMSNs, A-MSNs and PDMAEA-LPMSNs. The azide attachment only has a minor effect on the surface area, pore volume and pore size.
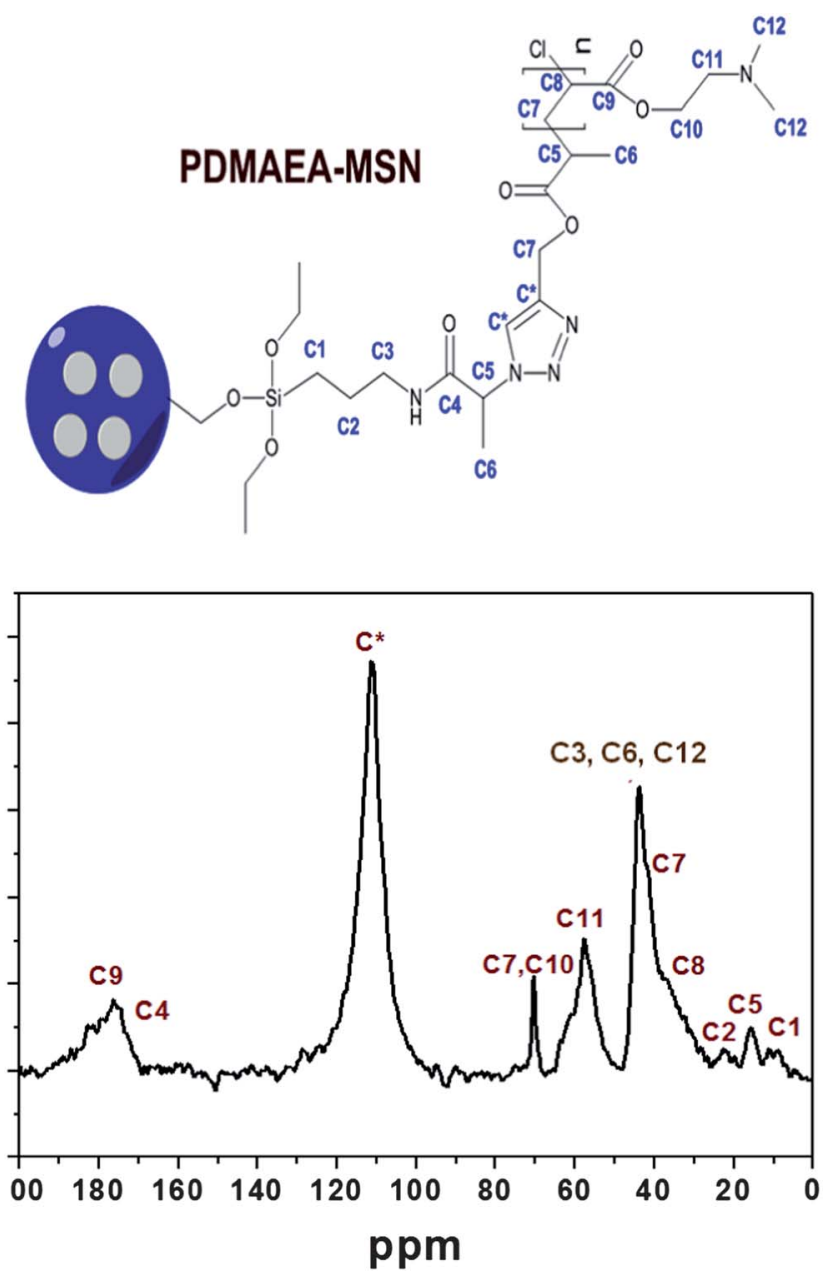

Fig. $3{ }^{13}$ C CP-MAS-NMR of PDMAEA-LPMSNs.

The values are similar to those for the LPMSNs. For both samples (LPMSNs and A-MSNs), the surface areas were approximately $400 \mathrm{~m}^{2} \mathrm{~g}$, the pore volume was $\sim 0.7 \mathrm{~cm}^{3} \mathrm{~g}^{-1}$ and cavity size was approximately $11 \mathrm{~nm}$ (Table S1†). However, the attachment of PDMAEA affected the physical properties. The BET surface area and pore volume values were reduced quite significantly to $105 \mathrm{~m}^{2} \mathrm{~g}^{-1}$ and $0.32 \mathrm{~cm}^{3} \mathrm{~g}^{-1}$. We propose that the high percentage of polymer (16\% measured from TGA) grafted onto the pore surface and subsequent pore entrance blockage is responsible for this reduction.

We designed the PDMAEA to be specifically attached on the MSN surface and not in the pores of the MSN. This makes the internal pores, which contain hydroxyl groups, accessible for drug molecules. For this reason, initially azide silane was grafted onto as-synthesized silica materials through a silylation reaction. The blocked pores of the as-synthesized MSNs ascertain that azide moieties only attach on the external surface. ${ }^{31}$ After surfactant removal, azide-MSNs (A-MSNs) were connected to PDMAEA via a click reaction. ${ }^{29,32}$ PDMAEA contains alkyne moieties which can chemically react with azide groups. The nitrogen sorption analysis (Fig. S1†) confirms that the attachment of azide only occurs on the 
Table 2 Summary of resonance of ${ }^{13} \mathrm{C}$ CP-MAS-NMR spectra for PDMAEA-LPMSNs

\begin{tabular}{|c|c|c|c|c|c|c|c|c|c|c|c|c|c|}
\hline PDMAEA-LPMSN & $\mathrm{C}^{1}$ & $\mathrm{C}^{2}$ & $\mathrm{C}^{3}$ & $\mathrm{C}^{4}$ & $\mathrm{C}^{5}$ & $\mathrm{C}^{6}$ & $\mathrm{C}^{7}$ & $\mathrm{C}^{8}$ & $\mathrm{C}^{9}$ & $\mathrm{C}^{10}$ & $\mathrm{C}^{11}$ & $\mathrm{C}^{12}$ & $\mathrm{C}^{*}$ \\
\hline Chemical shift (ppm) & 9.5 & 22.7 & 43.9 & 174.0 & 15.9 & 43.9 & 42.0 & 38.0 & 176.3 & 70.5 & 57.7 & 43.9 & 111.3 \\
\hline
\end{tabular}

external surface and does not affect the pore volume or size of the original LPMSNs.

To determine the binding and release of oligo DNA (mimic of siRNA) after conjugation with the PDMAEA-LPMSNs, we performed an agarose gel retardation assay for PDMAEALPMSN at different incubation times (1 and 2 days). Fig. 4 shows the assay for PDMAEA-LPMSNs and PEI-LPMSNs carried out at different N/P ratios (1 and 10) to test the binding efficiency of the nanoparticles. For this experiment, we used two types of PDMAEA-LPMSN (PDMAEA-LPMSN and PDMAEA-LPMSN-X) with different concentrations. PDMAEALPMSN-X was designed to contain half of the PDMAEA compared to the PDMAEA-LPMSNs. As a comparison, we also synthesized a composite of polyethyleneimine (PEI) and LPMSNs (PEI-LPMSNs). PEI is known to be the most widely used polycation for gene delivery and has been conjugated with MSNs for a similar purpose., ${ }^{8,12}$

As controls, we used oligo-DNA (lane-1) and LPMSN-oligo-DNA (lane-2). It was expected that the unbound oligo-DNA which was released from the particles would be observed as an emerging band on specific lanes. This band will not be detected as long as the oligo-DNA binds to the nanoparticles. ${ }^{24}$ After $30 \mathrm{~min}$ incubation, a mark can be observed from incomplete binding of oligo-DNA with the PDMAEA-LPMSNs and PDMAEA-LPMSN-X at $\mathrm{N} / \mathrm{P}=1$. In contrast, these marks were not detected in the case of the PDMAEA-LPMSNS and PDMAEA-LPMSN-X at N/P $=10$. These results confirmed that a higher $\mathrm{N} / \mathrm{P}$ ratio is required for better interaction and complete binding of biomolecules. A larger N/P ratio causes a better condensation of the complex of PDMAEA and oligo-DNA. ${ }^{23,24}$ Thus, a complex of PDMAEA-LPMSN and oligo-DNA at N/P ratio of 10 showed strong interaction with oligoDNA and maintained the complex stability.

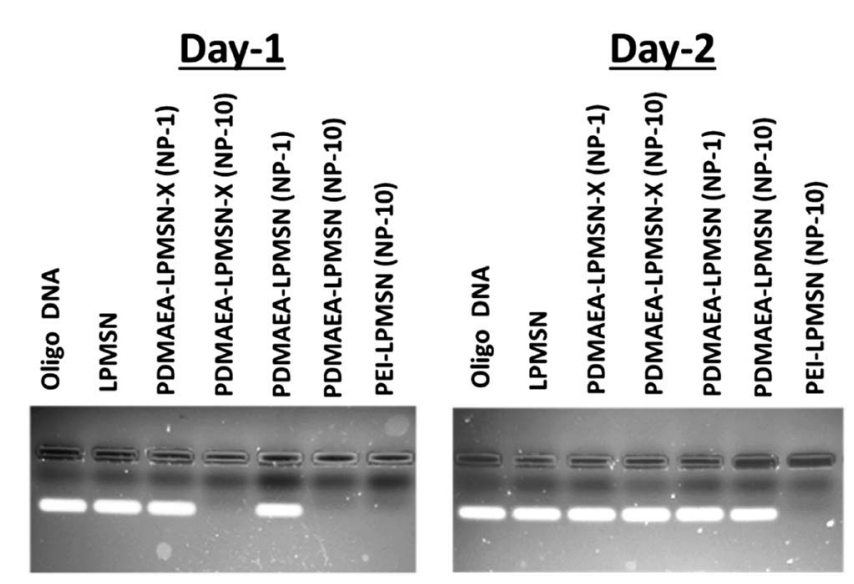

Fig. 4 Agarose gel retardation assay of PDMAEA-LPMSN and PEILPMSN after incubation for 30 minutes (Day-1) and after storage for 24 hours (Day-2).
The stable binding between carrier and oligo-DNA for the first few hours is very important to ascertain the delivery of the siRNA within the cytoplasm. ${ }^{23,24}$ Interestingly, after 24 hours incubation, smearing can be observed in most of the lanes except for the PEI-MSN lane. PEI is known to be very effective at complexing with plasmid DNA and siRNA. The multiple amine moieties within PEI enable strong interactions with the nucleic acids and cell membrane. Yet, PEI also has some drawbacks regarding the release of the nucleic acid from the complexes. ${ }^{16,17}$ The strong binding interaction between PEI and the biomolecules hinders release, thus no band is observed from the PEIMSN lane. In contrast, smearing can be detected from all the PDMAEA-LPMSN lanes. In the case of PDMAEA-LPMSN, PDMAEA is capable of maintaining its ionic strength for the first few hours before starting to degrade to non-toxic compounds, leading to temporary binding of oligo-DNA. ${ }^{2,24}$ After being released from PDMAEA-LPMSN, oligo-DNA can be observed in the gel, in agreement with previous reports. ${ }^{23,24}$ It was found that the polymer can maintain its binding with DNA for a sufficiently long period of time to transfect cells (around 4 hours) and then release the DNA inside the cells after 10 hours. ${ }^{23,24}$ Therefore we choose the PDMAEA-LPMSN composition rather than the conventional PEI functionalization reported in previous studies.

To enhance siRNA delivery, it is important for the carrier to escape from endosomal entrapment and deliver siRNA within the cytoplasm. We introduced Chl into the LPMSN's pores, which are also known as endosomal-escape inducing materials. ${ }^{\mathbf{1 4 1 9}} \mathrm{Chl}$ is weakly basic and can be attracted with negatively charged silanol groups. It is very soluble in water, with solubilities up to $1 \mathrm{mg} \mathrm{ml}{ }^{-1} \cdot{ }^{\mathbf{1 4 , 3 3}}$ However, the nature of the PDMAEA-LPMSNs which can be degraded in water makes the adsorption of Chl into PDMAEA-LPMSN in water impracticable. In addition, the nitrogen sorption shows that most of the entrance pores have been blocked after PDMAEA attachment, suggesting that the adsorption of Chl after polymer attachment is difficult. To optimize Chl adsorption, we carried out the adsorption after azide attachment (Scheme 1). Following surfactant removal, the pores of the azide-MSNs were accessible to Chl. The adsorption of Chl onto A-MSNs was conducted in water for 24 hours. $^{33}$ Then, PDMAEA attachment was carried in toluene. The loading amount of Chl in the PDMAEA-LPMSNs, based on UV analysis was $100 \mathrm{mg}$ $\mathrm{g}^{-1},\left(0.1 \mathrm{mg} \mathrm{mg}^{-1}\right.$ MSNs).

As shown in Scheme 1, PDMAEA-LPMSN is designed to codeliver siRNA and $\mathrm{Chl}$ in a controllable manner. After PDMAEA degradation, not only can the siRNA be released, but also the release of $\mathrm{Chl}$ is accelerated following the rupture of PDMAEA on the MSN's surface, which promotes endosomal escape of siRNA within the cytoplasm. To evaluate the cytotoxicity of the composite materials (PDMAEA-LPMSN and Chl-PDMAEA-LPMSN), we 


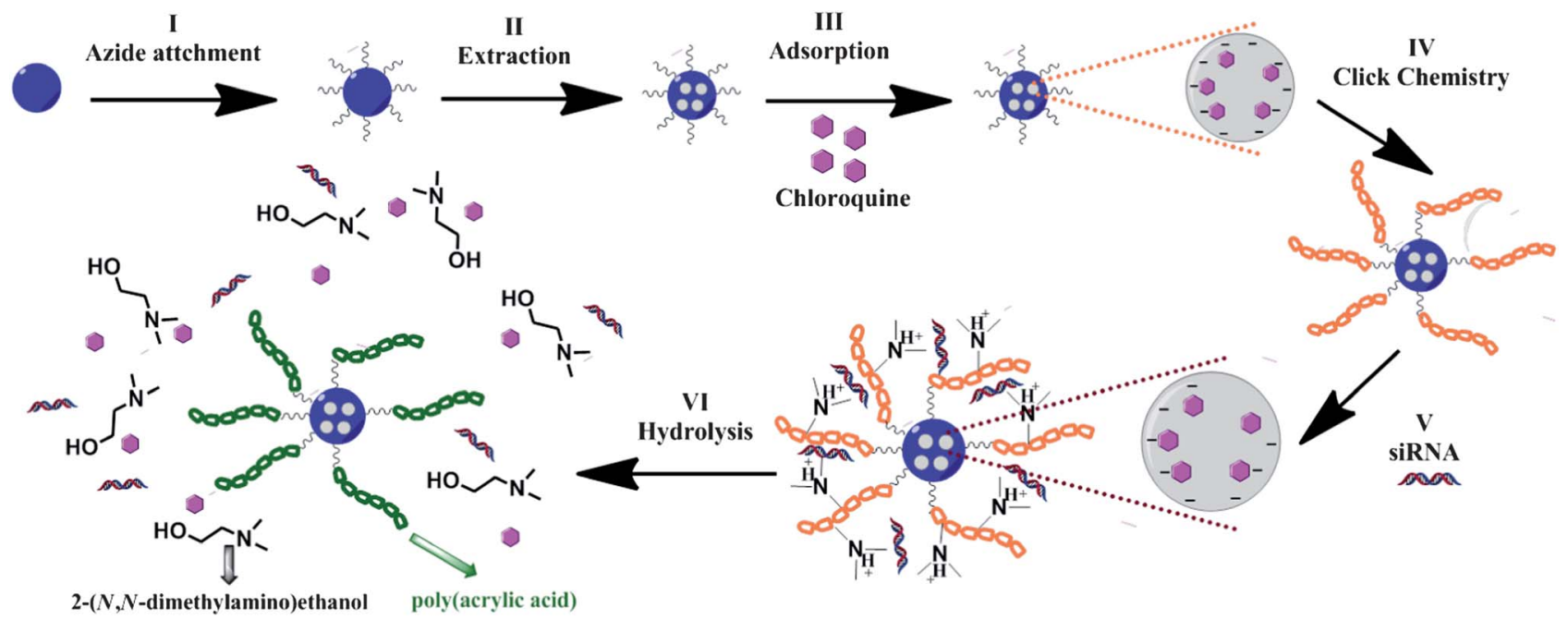

Scheme 1 Detailed mechanism of chloroquine loading and siRNA binding for dual delivery.

tested the effect of the particle's concentration on KHOS cell viability. Fig. 5 shows that the composite materials induced negligible toxicity, even at a very high concentration $400 \mu \mathrm{g} \mathrm{ml} l^{-1}$. The half maximal inhibitory concentration $\left(\mathrm{IC}_{50}\right)$ values of PDMAEA-LPMSN and Chl-PDMAEA-LPMSN were similar, approximately $1200 \mu \mathrm{g} \mathrm{ml}^{-1}$, which can be explained by the very low toxicity of PDMAEA ${ }^{23,24}$ and unmodified LPMSNs. ${ }^{15}$

Similarly to PDMAEA-LPMSNs, Chl-PDMAEA-LPMSNs did not affect the cell viability. This is in agreement with a previous report which showed that Chl loaded MSNs with a loading amount $0.15 \mathrm{mg} \mathrm{mg}^{-1}$ (close to Chl-PDMAEA-LPMSN, $0.1 \mathrm{mg}$ $\mathrm{mg}^{-1}$ ) have negligible effect on cytotoxicity. ${ }^{14}$ Our findings confirm that both PDMAEA-LPMSN and Chl-PDMAEA-LPMSN are safe to be used even at high concentrations.

Fig. 6 illustrates the cell uptake study of PDMAEA-LPMSN and Chl-PDMAEA-LPMSN. Confocal microscopy was used to observe the internalization of the particles. Firstly, all particles

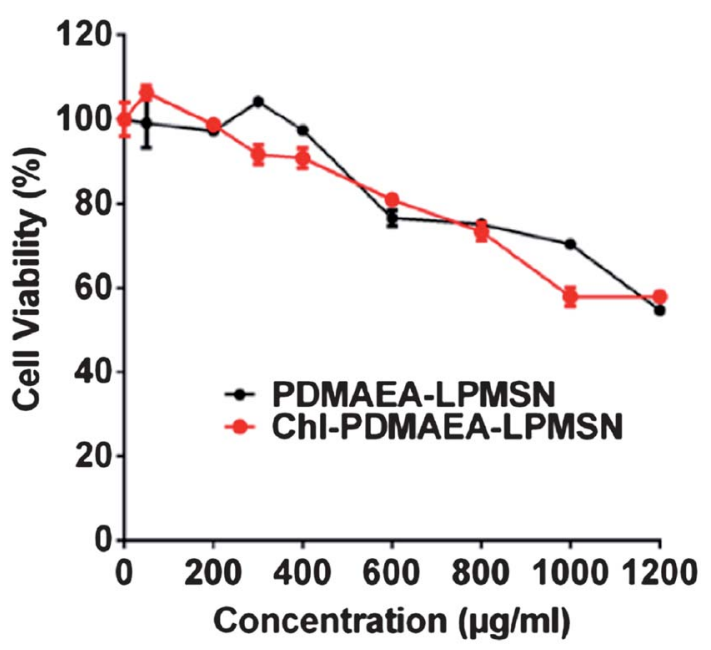

Fig. 5 Cytotoxicity test for PDMAEA-LPMSN and Chl-PDMAEALPMSN. were conjugated with oligo-DNA, they were then incubated with KHOS cell lines. To adequately follow adsorption and the cell internalization process, the oligo-DNA was labeled with cyanine dye (Cy3-oligo-DNA) to show red fluorescence. Cy3oligo-DNA itself without any nano-carriers did not show any red signal coming from $\mathrm{Cy} 3$, similar to that observed in the control group without any treatment. The blue signals observed were from DAPI stained nuclei. In contrast, both PDMAEA-LPMSNs and Chl-PDMAEA-LPMSNs conjugated with Cy3-oligo-DNA reveal red signals. These results demonstrated that the negatively charged oligo-DNA themselves cannot enter into the cells, while the functional nanoparticles (PDMAEALPMSNs and Chl-PDMAEA-LPMSNs) have the capacity to deliver the genetic molecules into the cells.

The polycation PDMAEA interacts with oligo-DNA and also the cell's membrane, essential for cellular uptake., ${ }^{8,15}$ Compared to PDMAEA-LPMSNs, it was observed that Chl-PDMAEA-LPMSNs showed a stronger and more homogeneous Cy3 signal. It is known that Chl is a DNA intercalator which has preferential binding towards the G-C sequence. ${ }^{34}$ We propose that $\mathrm{Chl}$ located adjacent to the external surface of the LPMSNs might improve the binding to oligo-DNA molecules. The stronger binding causes more oligo-DNA to be carried and delivered into the cells. After cellular uptake, Chl induces endosomal escape by its buffering capability. ${ }^{14}$ Consequently, the red signal coming from Cy3 is distributed homogeneously in the cytoplasm. In contrast, without Chl, the carriers are localised within discrete spots (see also Fig. 6). ${ }^{34}$

The ability of PDMAEA-LPMSN to co-deliver bio-functional siRNA and chloroquine (Chl) was investigated by using PLK1siRNA against polo-like kinase 1 and testing the cell toxicity in an osteosarcoma cell line, KHOS. Fig. 7 confirms that PDMAEALPMSN as a carrier has a negligible cell inhibition performance. Our previous study showed that PDMAEA as a single carrier has a low endosomal escape property, ${ }^{25}$ indicating that the siRNAs delivered by PDMAEA-LPMSNs, similarly to PDMAEA, cannot 


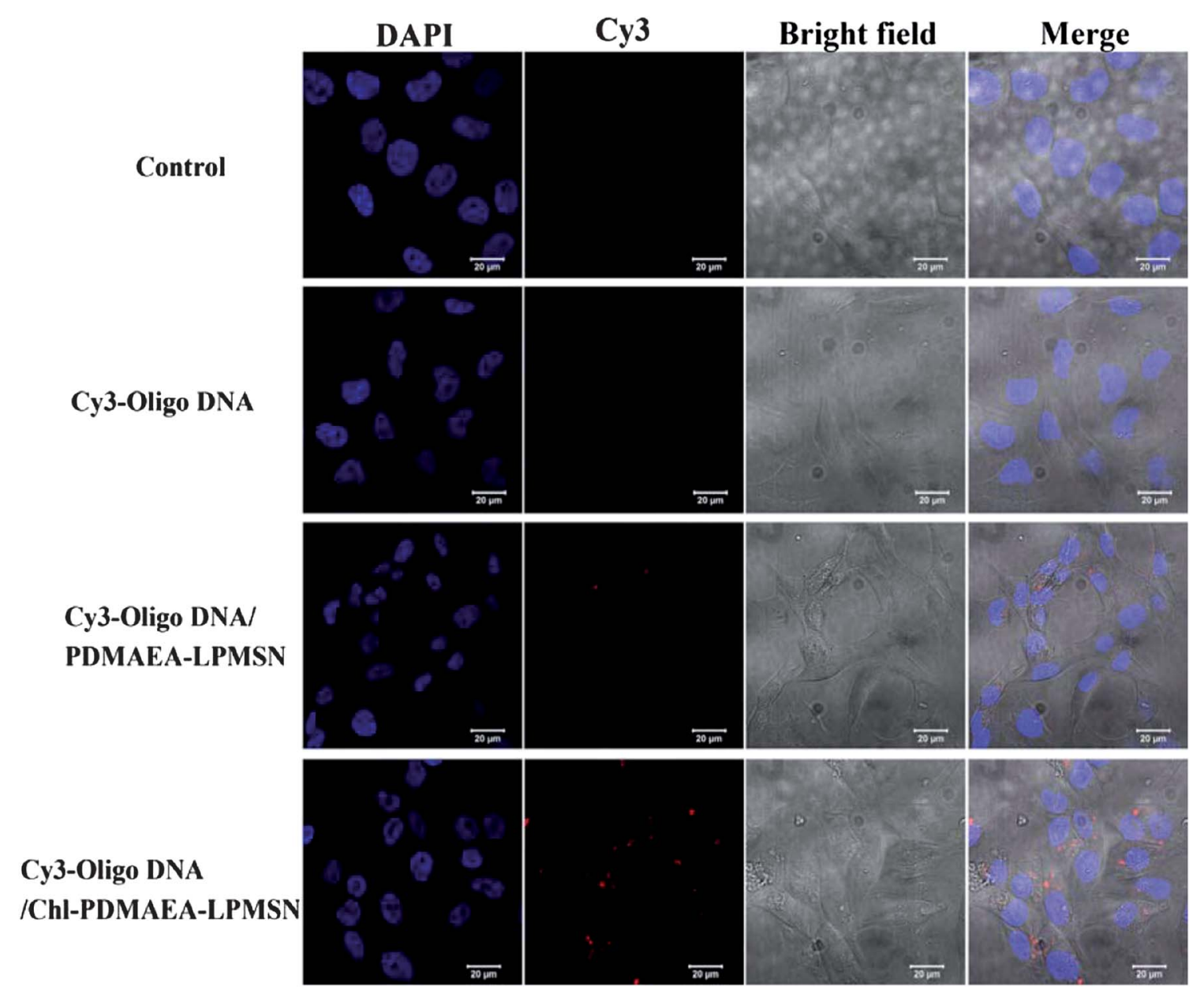

Fig. 6 Assessment of cell uptake by confocal microscopy. The cell uptake efficiency of PDMAEA-LPMSN and ChL-PDMAEA-LPMSN were examined by labeling the particles with a 21-nt oligo-DNA conjugated with Cy-3.

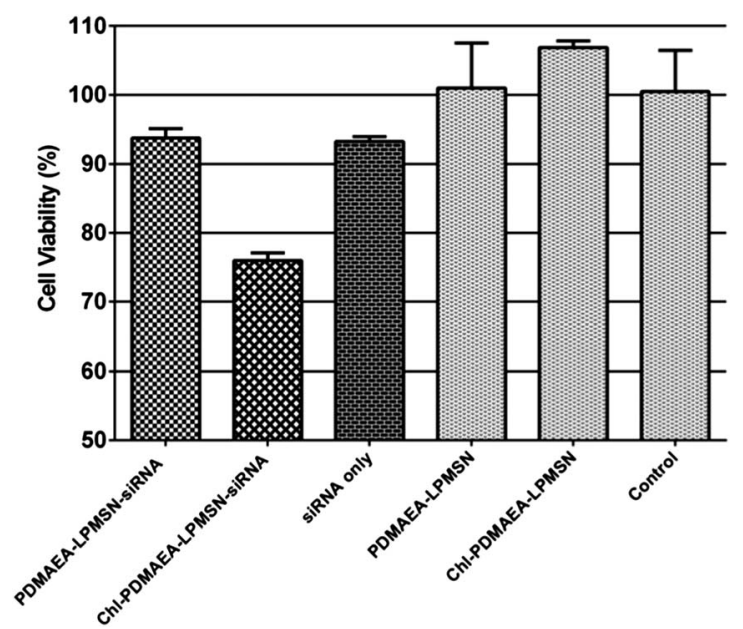

Fig. 7 Biological function analysis of PDMAEA-LPMSN and ChlPDMAEA-LPMSN based on delivering PLK1 siRNA in KHOS cells.

escape from endosomal entrapment to induce a silencing effect. ${ }^{25}$ In contrast, Chl-PDMAEA-LPMSN induces a reasonably significant decrease in cellular viability (25\%). Our results have shown that although the actual benefit of PDMAEA as a single carrier for gene silencing is limited, ${ }^{25}$ the conjugation with LPMSNs offers more opportunities for the fabrication of effective and multi-functional nano-carriers.

\section{Conclusion}

In this study, a novel gene carrier with selected properties: degradability, low toxicity and high capacity was prepared by grafting "self-catalyzed degradation" PDMAEA onto the surface of large pore and cubic mesostructured mesoporous silica nanoparticles to produce an efficient gene carrier: PDMAEALPMSNs. The composite materials have very low toxicity even at a very high concentration of $400 \mu \mathrm{g} \mathrm{ml}{ }^{-1}$. The degradable PDMAEA enables the release of siRNA after endocytosis. The chloroquine loaded inside the nanopores allows the cargo molecules to escape from endosomal entrapment. These results demonstrate the potential of PDMAEA-LPMSNs as a gene carrier. To fully utilise the potential of PDMAEA-LPMSNs, it is expected that chemotherapy drugs could also be carried, offering multi-functional nano-carriers for dual delivery applications. 


\section{Acknowledgements}

We thank the Australian Research Council for financial support. We acknowledge the Australian National Fabrication Facility and the Australian Microscopy \& Microanalysis Research Facility at the Centre for Microscopy and Microanalysis, The University of Queensland and Dr Barry Wood from The Brisbane Surface Analysis Facility for support in XPS analysis and Dr Ekaterina Strounina from Centre for Advanced Imaging for NMR analysis. S.B.H gratefully acknowledges the UQIRTA scholarship from The University of Queensland.

\section{Notes and references}

1 C. R. Sibley, Y. Seow and M. J. A. Wood, Mol. Ther., 2010, 18, 466-476.

2 D. Reischl and A. Zimmer, Nanomedicine, 2009, 5, 8-20.

3 B. Ozpolat, A. K. Sood and G. Lopez-Berestein, J. Intern. Med., 2010, 267, 44-53.

4 X. Gao and L. Huang, Biochemistry, 1996, 35, 1027-1036.

5 I. Ojea-Jimenez, L. Garcia-Fernandez, J. Lorenzo and V. F. Puntes, ACS Nano, 2012, 6, 7692-7702.

6 S. Jiang, A. A. Eltoukhy, K. T. Love, R. Langer and D. G. Anderson, Nano Lett., 2013, 13, 1059-1064.

7 F. Gao, P. Botella, A. Corma, J. Blesa and L. Dong, J. Phys. Chem. B, 2009, 113, 1796-1804.

8 T. Xia, M. Kovochich, M. Liong, H. Meng, S. Kabehie, S. George, J. I. Zink and A. E. Nel, ACS Nano, 2009, 3, 32733286.

9 X. He, K. Wang, W. Tan, B. Liu, X. Lin, S. Huang, D. Li, C. He and J. Li, Chin. Sci. Bull., 2003, 48, 223-228.

10 M.-H. Kim, H.-K. Na, Y.-K. Kim, S.-R. Ryoo, H. S. Cho, K. E. Lee, H. Jeon, R. Ryoo and D.-H. Min, ACS Nano, 2011, 5, 3568-3576.

11 H.-K. Na, M.-H. Kim, K. Park, S.-R. Ryoo, K. E. Lee, H. Jeon, R. Ryoo, C. Hyeon and D.-H. Min, Small, 2012, 8, 1752-1761.

12 H. Meng, M. Liong, T. Xia, Z. Li, Z. Ji, J. I. Zink and A. E. Nel, ACS Nano, 2010, 4, 4539-4550.

13 A. M. Chen, M. Zhang, D. Wei, D. Stueber, O. Taratula, T. Minko and H. He, Small, 2009, 5, 2673-2677.

14 S. R. Bhattarai, E. Muthuswamy, A. Wani, M. Brichacek, A. L. Castaneda, S. L. Brock and D. Oupicky, Pharm. Res., 2010, 27, 2556-2568.
15 S. B. Hartono, W. Gu, F. Kleitz, J. Liu, L. He, A. P. J. Middelberg, C. Yu, G. Q. Lu and S. Z. Qiao, ACS Nano, 2012, 6, 2104-2117.

16 G. Lin, R. Hu, W.-C. Law, C.-K. Chen, Y. Wang, H. L. Chin, Q. T. Nguyen, C. K. Lai, H. S. Yoon, X. Wang, G. Xu, L. Ye, C. Cheng and K.-T. Yong, Small, 2013, 9, 2757-2763.

17 A. A. Eltoukhy, D. Chen, C. A. Alabi, R. Langer and D. G. Anderson, Adv. Mater., 2013, 25, 1487-1493.

18 D. M. Dykxhoorn, C. D. Novina and P. A. Sharp, Nat. Rev. Mol. Cell Biol., 2003, 4, 457-467.

19 M. Wang, X. Li, Y. Ma and H. Gu, Int. J. Pharm., 2013, 448, 51-57.

20 B. Chang, D. Chen, Y. Wang, Y. Chen, Y. Jiao, X. Sha and W. Yang, Chem. Mater., 2013, 25, 574-585.

21 R. Namgung and W. J. Kim, Small, 2012, 8, 3209-3219.

22 C. A. Hong, J. S. Kim, S. H. Lee, W. H. Kong, T. G. Park, H. Mok and Y. S. Nam, Adv. Funct. Mater., 2013, 23, 316322.

23 N. P. Truong, Z. Jia, M. Burges, N. A. J. McMillan and M. J. Monteiro, Biomacromolecules, 2011, 12, 1876-1882.

24 N. P. Truong, Z. Jia, M. Burgess, L. Payne, N. A. J. McMillan and M. J. Monteiro, Biomacromolecules, 2011, 12, 3540-3548.

25 N. P. Truong, W. Gu, I. Prasadam, Z. Jia, R. Crawford, Y. Xiao and M. J. Monteiro, Nat. Commun., 2013, 4, 1902.

26 Y. Han and J. Y. Ying, Angew. Chem., Int. Ed., 2005, 44, 288292.

27 V. Percec, T. Guliashvili, J. S. Ladislaw, A. Wistrand, A. Stjerndahl, M. J. Sienkowska, M. J. Monteiro and S. Sahoo, J. Am. Chem. Soc., 2006, 128, 14156-14165.

28 D. A. Egede, S. Hvilsted, T. S. Hansen and N. B. Larsen, Macromolecules, 2008, 41, 4321-4327.

29 J. Nakazawa, B. J. Smith and T. D. P. Stack, J. Am. Chem. Soc., 2012, 134, 2750-2759.

30 A. Schlossbauer, D. Schaffert, J. Kecht, E. Wagner and T. Bein, J. Am. Chem. Soc., 2008, 130, 12558-12559.

31 L. Xu, F. Xu, F. Chen, J. Yang and M. Zhong, J. Nanomater., 2012, 457967.

32 N. Moitra, P. Trens, L. Raehm, J.-O. Durand, X. Cattoen and M. W. C. Man, J. Mater. Chem., 2011, 21, 13476-13482.

33 V. Sanz, C. Tilmaciu, B. Soula, E. Flahaut, H. M. Coley, S. R. P. Silva and J. McFadden, Carbon, 2011, 49, 5348-5358. 34 S. Yang, D. J. Coles, A. Esposito, D. J. Mitchell, I. Toth and R. F. Minchin, J. Controlled Release, 2009, 135, 159-165. 


\section{Supporting Information}

\section{Functionalized Large Pore Mesoporous Silica Nanoparticles for Gene Delivery featuring Time-dependent Release and Co- delivery $\dagger$}

Sandy Budi Hartono, ${ }^{\mathrm{a}}$ Nghia Truong Phuoc, ${ }^{\mathrm{a}}$ Meihua Yu, ${ }^{\mathrm{a}}$ Zhongfan Jia, ${ }^{\mathrm{a}}$ Michael Monteiro, ${ }^{, a}$ Shizhang Qiao, ${ }^{*, b}$ Chengzhong $\mathbf{Y u}^{*, a}$

${ }^{a}$ Australian Institute for Bioengineering and Nanotechnology, The University of Queensland, Brisbane, QLD 4072, Australia.

${ }^{\mathrm{b}}$ School of Chemical Engineering, The University of Adelaide, Adelaide, Australia

*Email:m.monteiro@uq.edu.au; s.qiao@adelaide.edu.au; c.yu@uq.edu.au

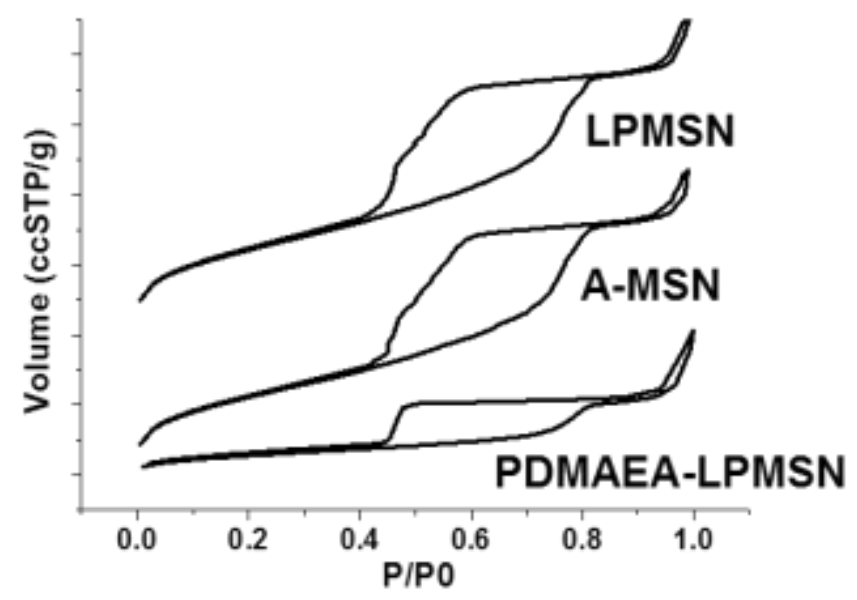

Fig. S1 Nitrogen sorption curves of LPMSN, A-MSN and PDMAEA-LPMSN

Table S1 Physicochemical properties of samples

\begin{tabular}{cccc}
\hline Sample & $\begin{array}{c}\text { BET Surface Area } \\
\left(\mathbf{m}^{2} / \mathbf{g}\right)\end{array}$ & $\begin{array}{c}\text { Pore Volume } \\
(\mathbf{c c} / \mathbf{g})\end{array}$ & $\begin{array}{c}\text { Cavity } \\
(\mathbf{n m})\end{array}$ \\
\hline LPMSN & 451 & 0.70 & 11.0 \\
A-MSN & 415 & 0.67 & 11.0 \\
PDMAEA-LPMSN & 105 & 0.32 & 10.2 \\
\hline
\end{tabular}



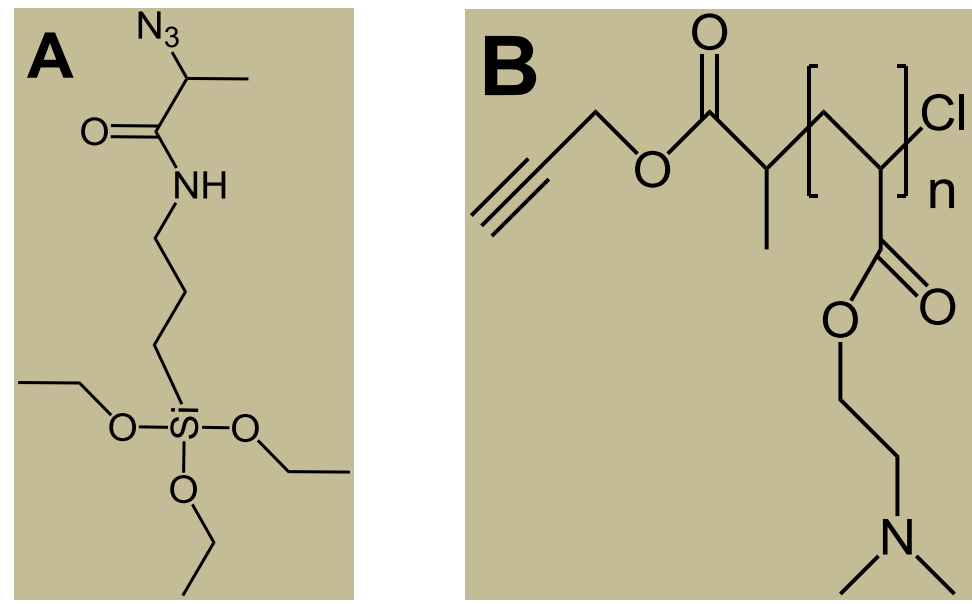

Fig. S2 2-azido-N-(3-(triethoxy silyl)propyl)propanamide or Azide silane (A) and poly(2dimethylaminoethyl acrylate) (PDMAEA) (B)

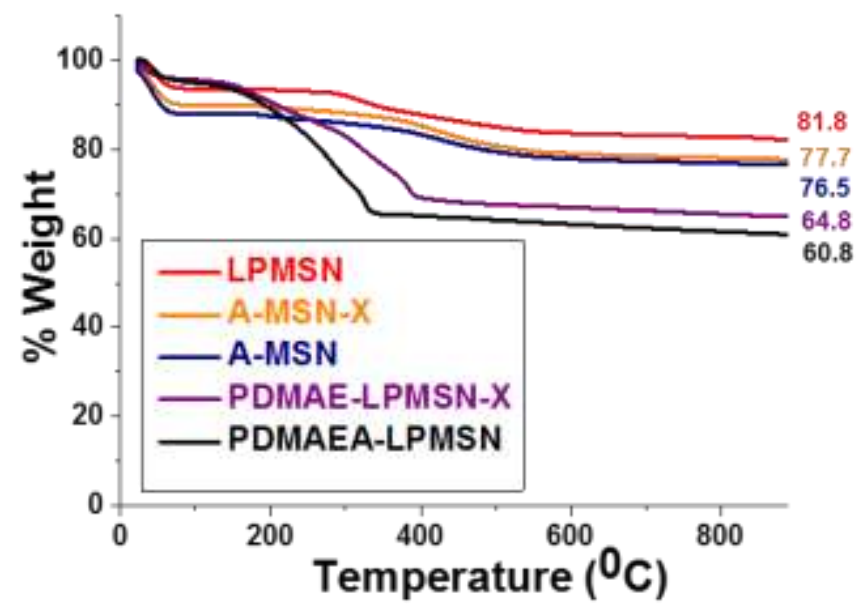

Fig. S3 TGA analysis of LPMSN and functionalised LPMSN 

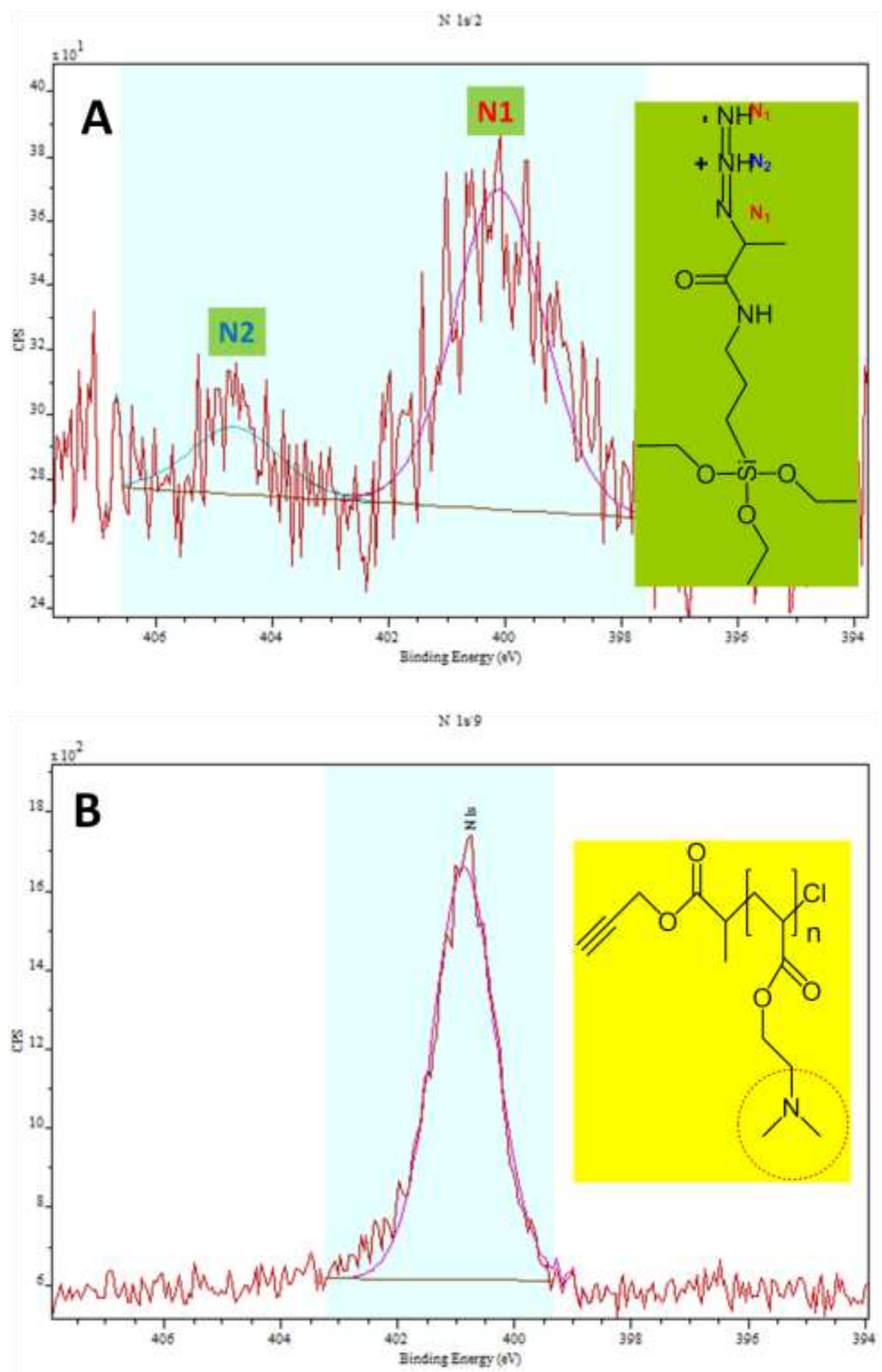

Fig. S4 High resolution XPS analysis of N1s spectra for (A) A-MSN and (B) PDMAEA-LPMSN 